Retrospective Study

\title{
New Levels of Vertebral Compression Fractures after Percutaneous Kyphoplasty: Retrospective Analysis of Styles and Risk Factors
}

Lei Ning, MD, Shuanglin Wan, MD, Chao Liu, MD, Zhaobo Huang, MD, Hongxin Cai, MD, and Shunwu Fan, MD

rthopaedic Surgery, Sir Run Run Shaw Hospital, School of Medicine, Zhejiang University, 3 East Qing Chun Road, Hangzhou 310016, China Address Correspondence:

Shuanglin Wan, MD Department of Orthopaedic Surgery, Sir Run Run Shaw Hospital, School of Medicine, Zhejiang University, 3 East Qing Chun Road, Hangzhou 310016, China E-mail:

wanshuanglin@aliyun.com

Disclaimer: There was no external funding in the preparation of this manuscript. Conflict of interest: Each author certifies that he or she, or a member of his or her immediate family, has no commercial association (i.e., consultancies, stock ownership, equity interest, patent/licensing arrangements, etc.) that might pose a conflict of interest in connection with the submitted manuscript.

Manuscript received: 10-10-2014 Revised manuscript received: 03-20-2015

Accepted for publication: 06-01-2015

Free full manuscript: www.painphysicianjournal.com
Background: The causes of subsequent vertebral fractures after kyphoplasty are debated. It is reported that most new vertebral fractures after kyphoplasty develop in adjacent vertebrae.

Objectives: We explored whether kyphoplasty increases the incidence of adjacent vertebral fractures and identified risk factors for new vertebral compression fractures (VCFs) after kyphoplasty.

Study Design: Retrospective study.

Setting: Inpatient population of a single center.

Methods: We studied 356 patients treated with kyphoplasty from January 2008 to March 2012 Among those patients, there were 35 new VCFs after kyphoplasty. Subsequently, these patients were divided into 2 groups: an "adjacent fracture" group and a "nonadjacent fracture" group. In addition, all patients treated with kyphoplasty were further assigned to either a "new fracture" group or a "no fracture" group.

Results: The occurrence of new VCFs in the "nonadjacent fracture" group was significantly higher than that in the "adjacent fracture" group. The average bone mineral density (BMD) of the spine was -3.95 in the "new fracture" group and -2.86 in the "no fracture" group. The risk of new vertebral fracture increased as the bone mineral density decreased $(P<0.05)$. The morbidity of women was significantly higher in the "new fracture" group $(94.29 \%)$ than in the "no fracture" group $(77.88 \%)(P=0.025)$.

Limitations: Retrospective study at a single center.

Conclusion: New VCFs after kyphoplasty occurred most often in nonadjacent vertebrae. VCFs after kyphoplasty were common in patients with low bone mineral density and in women, suggesting that osteoporosis is an underlying mechanism.

Institutional Review: This study was approved by the institutional review board.

Key words: Percutaneous kyphoplasty, vertebral compression fractures, bone mineral density, polymethylmethacrylate, adjacent vertebral fracture

Pain Physician 2015; 18:565-572
P ercutaneous percutaneous kyphoplasty (PKP) and vertebroplasty (PVP) are widely accepted treatments for symptomatic osteoporotic vertebral compression fractures (VCFs). This procedure not only stabilizes the vertebral body but also relieves the pain. Immediate and significant pain relief is achieved in $60-90 \%$ of patients who undergo percutaneous vertebroplasty $(1,2)$. However, new vertebral fractures after kyphoplasty have raised concerns about the procedure. Most articles report that almost all vertebral fractures after vertebroplasty occur in adjacent vertebrae, but we find that the 
incidence of new fractures is highest in nonadjacent vertebrae. The causes of post-procedure fractures are debated. The severity of osteoporosis and the stiffness of implanted bone cements are possible causes $(3,4)$.

The objective of this research is to identify the levels of subsequent vertebral fractures and to explore the relationships between newly developed vertebral fractures after PKP and various risk factors [age, gender, body weight, body height, body mass index (BMI), bone mineral density (BMD) score of the spine, treated vertebral level, intradiscal cement leakage, restoration rate of anterior/middle vertebral height, and volume of polymethylmethacrylate (PMMA)].

\section{Methods}

\section{Patients}

A total of 421 patients with symptomatic VCFs were treated with PKP in our hospital from January 2008 to March 2012. Patients with diseases such as multiple myeloma or metastatic pathologic fractures were excluded. Patients with initial fractures of 3 segments or more and 3 or more recurrent fractures were excluded.

In total, 356 patients ( 283 women, 73 men) with 434 levels were enrolled in this study. Patients were followed up after PKP for a mean duration of $17.59 \pm 9.92$ months (6 -50 months). The mean age of the patients was 70.10 \pm 8.69 years (51 to 91 years) at the time of operation. Among those patients, 35 (51 levels) incurred a new vertebral fracture after kyphoplasty. All patients were as- signed into "new fracture" (35 patients) or "no fracture" (321 patients) groups. Patients in the "new fracture" group were subdivided according to the fracture level. There were 14 patients in the "adjacent fracture" group and 21 in the "nonadjacent fracture" group.

\section{Surgical Procedure}

PKP was performed according to standardized procedures, and all procedures were performed with the aid of fluoroscopy. Initially, each patient was placed in the prone position and provided local anesthesia. Under fluoroscopic guidance, a transpedicular approach was utilized to place trocar and cannula systems through the pedicles into the fractured vertebral body. Next, the trocar was removed and a balloon was inserted through each guiding cannula. The balloon was inflated and removed from the vertebral body for cement introduction. Finally, the cement (PMMA) was injected into the vertebral body. The procedure was immediately stopped if cement reached the posterior $1 / 4$ of the vertebral body or if there was significant leakage.

\section{Data Collection}

Information statistics, including the treated vertebral level, the interval between initial intervention with PKP and the diagnosis of subsequent fractures, age, gender, body weight, body height, BMI, BMD, intradiscal cement leakage, volume of PMMA, and anterior/middle vertebral height (Fig. 1) were obtained from clinical records. The BMD was measured by dual-energy $x$-ray absorptiometry.

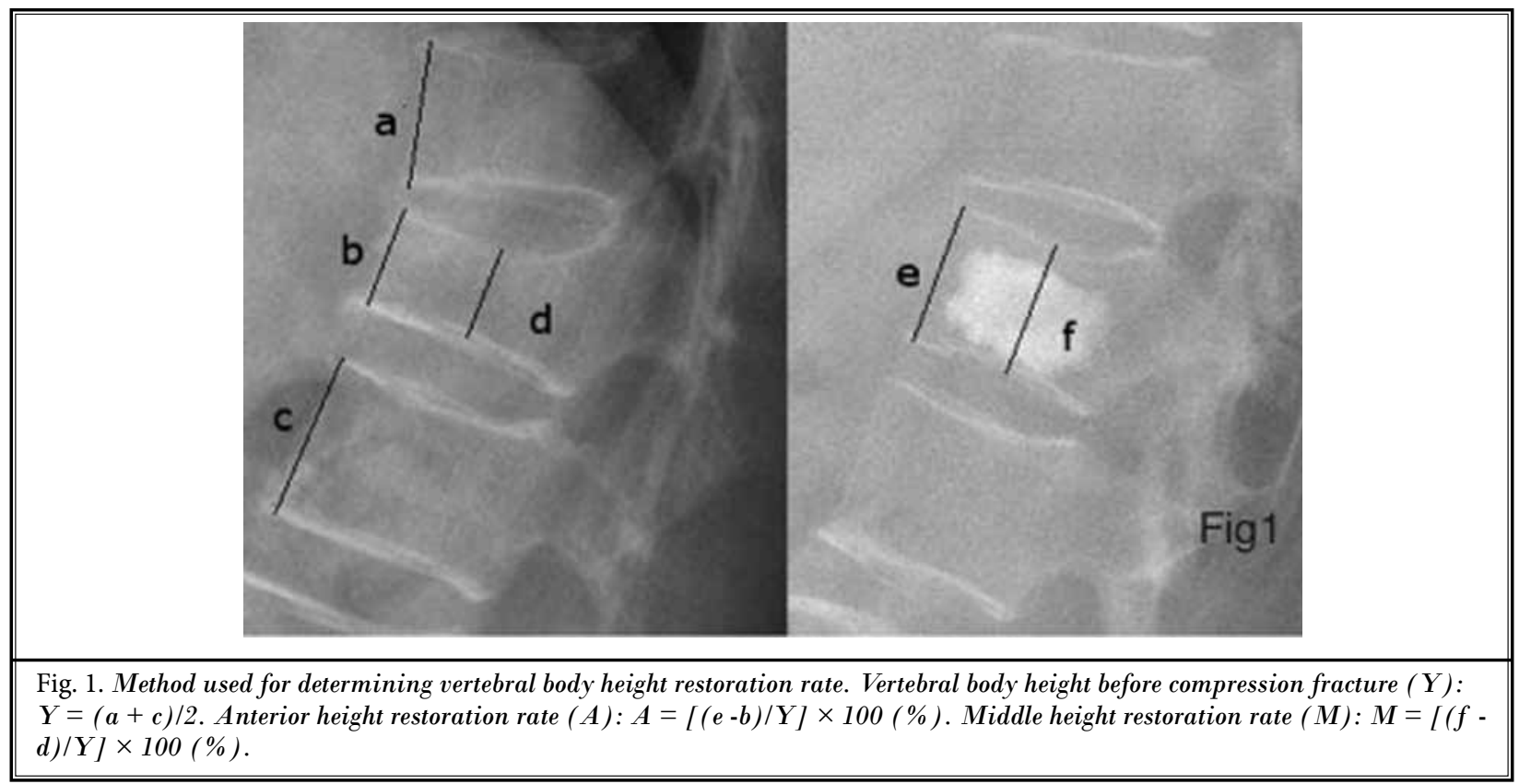




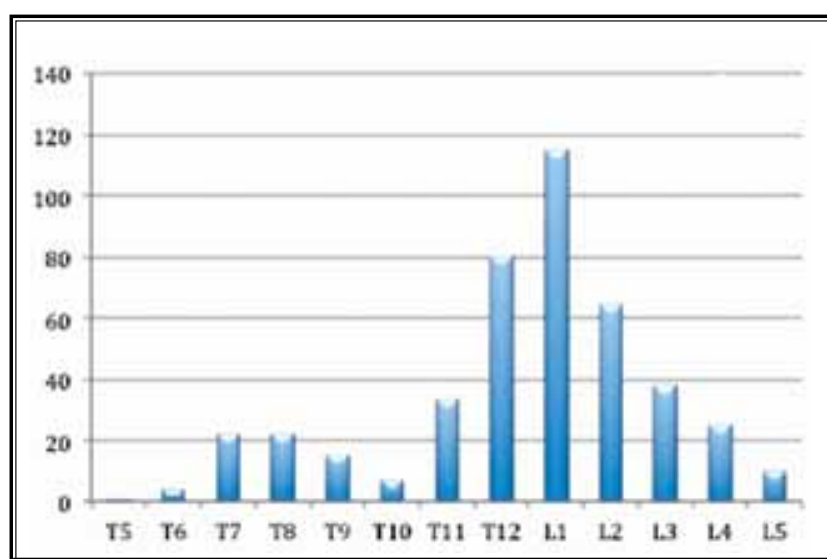

Fig. 2. Number of treatments per vertebral level.

\section{Statistical Analysis}

Descriptive statistics are expressed as the mean \pm standard deviation for continuous variables and as percentages for categorical variables. Differences between patients with and without new VCFs were assessed by t-test for continuous variables and chi-square test for categorical variables. Estimates of the risk of new VCF were based on the Kaplan-Meier method, with censoring on the date of death or the latest follow-up assessment. Statistical analysis was performed with the Predictive Analytics Software Statistics 16.0 program (SPSS Inc., Chicago, IL, USA).

\section{Result}

Among the 356 kyphoplasty-treated patients, 35 (9.8\%, 33 women, 2 men) experienced new VCFs following kyphoplasty. The level of initial fracture occurred between T5 and L5 but was most prevalent at the thoracolumbar junction (T12-L1), with L1 as the most common fracture location (Fig. 2).

Out of the 35 new VCF patients following PKP, 21 $(60 \%)$ were nonadjacent fractures and $14(40 \%)$ were adjacent fractures. Among the patients with subsequent vertebral fractures, 33 patients were women and 2 were men (one adjacent fracture, one nonadjacent fracture) (Table 1). The distribution of adjacent vertebral fractures and nonadjacent vertebral fractures is shown in Fig. 3. The one-year symptomatic fracture-free rate after PKP was $96.35 \%$ by the Kaplan-Meier estimate (Fig. 4). The mean interval was $18.04 \pm 14.21$ months $(0.03-48$ months) between the initial kyphoplasty and the subsequent fractures.

The characteristics of patients in the "adjacent fracture" group versus the "nonadjacent fracture" group are summarized in Table 2 . There was no significant dif-
Table 1. Characteristics of patients with subsequent vertebral fractures after PKP.

\begin{tabular}{|c|c|c|c|c|c|}
\hline Patients & Gender & $\begin{array}{c}\text { First } \\
\text { fracture } \\
\text { level }\end{array}$ & $\begin{array}{c}\text { New } \\
\text { fracture } \\
\text { level }\end{array}$ & BMD & $\begin{array}{c}\text { Fracture } \\
\text { interval } \\
\text { time } \\
\text { (month) }\end{array}$ \\
\hline $1^{\star}$ & F & L1 & T11 & -4.3 & 36.00 \\
\hline $2^{*}$ & $\mathrm{~F}$ & L3,L5 & L1 & -3.5 & 0.67 \\
\hline $3^{*}$ & M & T12 & T6 & -4 & 8.00 \\
\hline $4^{*}$ & $\mathrm{~F}$ & $\mathrm{~T} 8, \mathrm{~T} 11$ & T6 & -4.5 & 20.00 \\
\hline $5^{*}$ & $\mathrm{~F}$ & L4 & $\mathrm{L} 2$ & -4.1 & 3.00 \\
\hline $6^{*}$ & $\mathrm{~F}$ & T7 & $\mathrm{T} 10$ & -4.3 & 32.00 \\
\hline $7^{*}$ & $\mathrm{~F}$ & $\mathrm{~L} 1, \mathrm{~L} 4$ & T11 & -3.7 & 39.00 \\
\hline $8^{*}$ & $\mathrm{~F}$ & $\mathrm{~T} 11, \mathrm{~L} 1$ & T9,L4 & -3 & 0.73 \\
\hline $9^{*}$ & $\mathrm{~F}$ & T9 & T12 & -3.6 & 0.67 \\
\hline $10^{*}$ & $\mathrm{~F}$ & $\mathrm{~T} 12, \mathrm{~L} 1$ & $\mathrm{~T} 8$ & -3.7 & 40.00 \\
\hline $11^{*}$ & $\mathrm{~F}$ & T11 & L3 & -3.8 & 25.00 \\
\hline $12^{*}$ & $\mathrm{~F}$ & $\mathrm{~T} 7$ & T9 & -4.5 & 36.00 \\
\hline $13^{*}$ & $\mathrm{~F}$ & T10 & $\mathrm{L} 1$ & -4.2 & 17.00 \\
\hline $14^{*}$ & $\mathrm{~F}$ & $\mathrm{~T} 8$ & $\mathrm{~L} 1$ & -3.5 & 12.00 \\
\hline $15^{\star}$ & $\mathrm{F}$ & T12 & T7 & -3.4 & 19.00 \\
\hline $16^{*}$ & $\mathrm{~F}$ & $\mathrm{~T} 7$ & T9 & -4.3 & 4.67 \\
\hline $17^{\star}$ & $\mathrm{F}$ & T12 & L4 & -4.3 & 15.00 \\
\hline $18^{*}$ & $\mathrm{~F}$ & $\mathrm{~L} 2, \mathrm{~L} 4$ & T12 & -4.2 & 17.00 \\
\hline $19^{*}$ & $\mathrm{~F}$ & $\mathrm{~T} 8$ & $\mathrm{~L} 1, \mathrm{~T} 12$ & -4.6 & 13.00 \\
\hline $20^{*}$ & $\mathrm{~F}$ & T12 & $\mathrm{T} 8$ & -4.3 & 13.67 \\
\hline $21^{*}$ & $\mathrm{~F}$ & T6,T8 & T10,T12 & -4.4 & 20.00 \\
\hline $22 \#$ & M & $\mathrm{T} 10 \otimes \mathrm{T} 12$ & T9 & -4.3 & 41.00 \\
\hline 23\# & $\mathrm{F}$ & T10,L1 & T9,T11 & -3.6 & 12.00 \\
\hline $24 \#$ & $\mathrm{~F}$ & $\mathrm{~L} 1, \mathrm{~L} 2$ & T12 & -2.6 & 23.00 \\
\hline $25 \#$ & $\mathrm{~F}$ & $\mathrm{~T} 8, \mathrm{~T} 10$ & T9 & -4.6 & 0.33 \\
\hline $26 \#$ & $\mathrm{~F}$ & $\mathrm{~T} 7$ & T8 & -2.9 & 13.00 \\
\hline $27 \#$ & $\mathrm{~F}$ & $\mathrm{~L} 1, \mathrm{~L} 2$ & T12 & -5.4 & 40.00 \\
\hline $28 \#$ & $\mathrm{~F}$ & T11 & T12 & -4.5 & 22.00 \\
\hline 29\# & $\mathrm{F}$ & $\mathrm{L} 1, \mathrm{~L} 2$ & T8,T12 & -3.8 & 30.00 \\
\hline 30\# & $\mathrm{F}$ & L4 & $\mathrm{L} 2, \mathrm{~L} 3$ & -4 & 0.03 \\
\hline $31 \#$ & $\mathrm{~F}$ & T8,T9 & T10 & -2.9 & 0.43 \\
\hline $32 \#$ & $\mathrm{~F}$ & $\mathrm{~L} 1$ & T12 & -3.4 & 1.06 \\
\hline 33\# & $\mathrm{F}$ & $\mathrm{L} 2, \mathrm{~L} 4$ & L3 & -4.2 & 6.00 \\
\hline $34 \#$ & $\mathrm{~F}$ & L5 & L4 & -3.8 & 48.00 \\
\hline 35\# & $\mathrm{F}$ & $\mathrm{T} 12, \mathrm{~L} 3$ & T11 & -3.8 & 22.00 \\
\hline
\end{tabular}

nonadjacent vertebral fracture,\# adjacent vertebral fracture. 


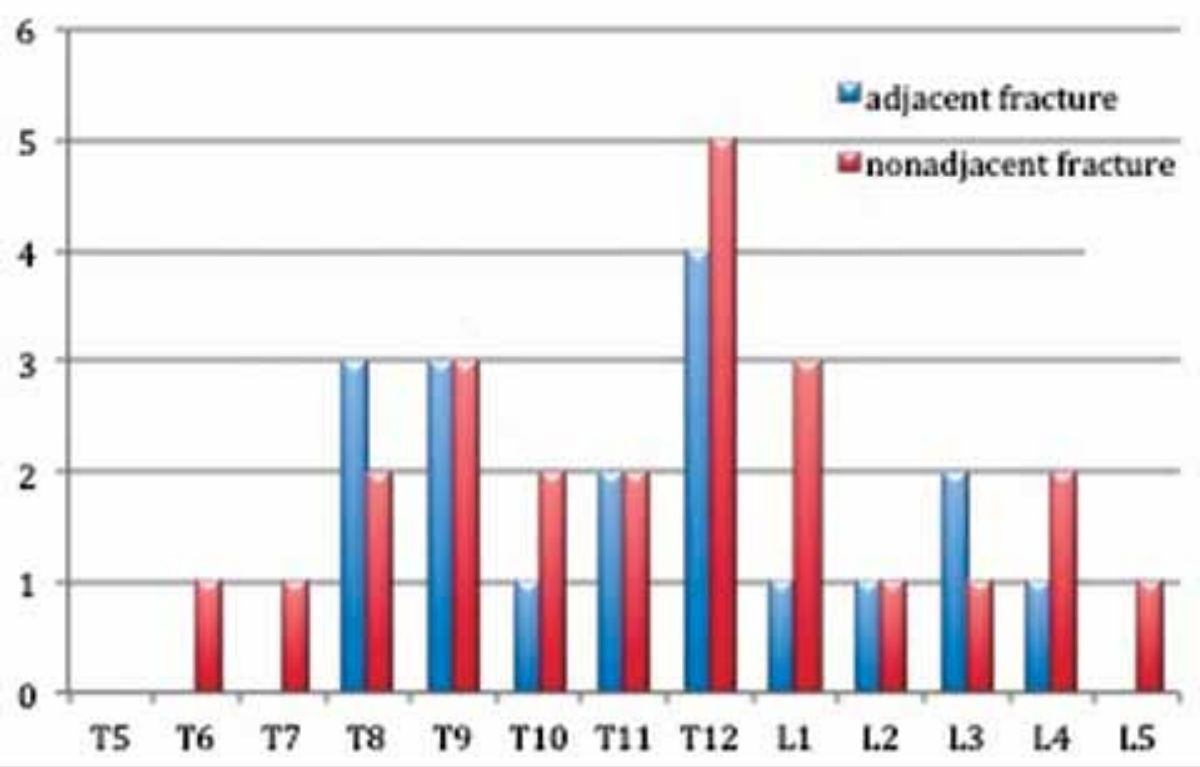

Fig. 3. Location of adjacent and nonadjacent level fractures. Most re-fractures were located at the mid-thoracic (T8-9) and thoracolumbar (T12-L1) regions of the spine. The distribution of nonadjacent-level fractures has no significant difference from that of adjacent-level fractures.

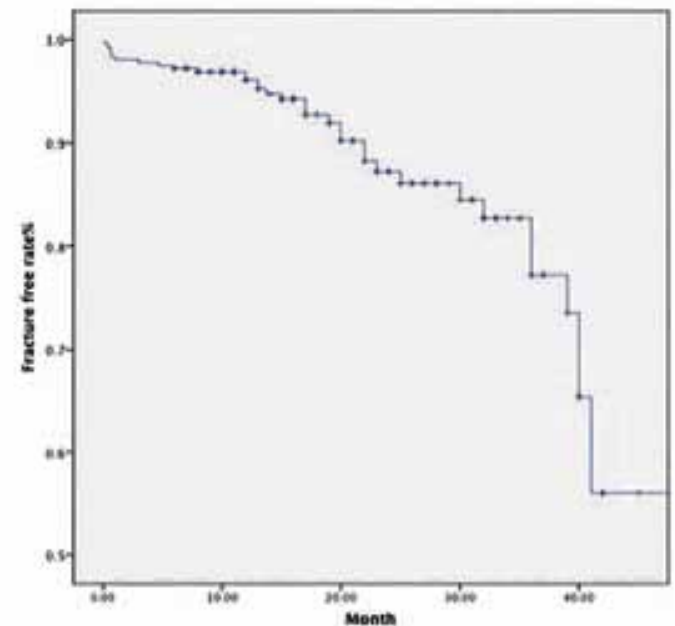

Fig. 4. The Kaplan-Meier survival curve shows the estimated fracture free rate of vertebral after kyphoplasty.

ference between the 2 groups. The mean body weight and the mean BMI in the "adjacent fracture" group were greater than in the "nonadjacent fracture" group, although this difference was not statistically significant $(P>0.05)$. In the group with adjacent fracture, 6 of 14 patients $(42.86 \%)$ had a BMI of more than $25 \mathrm{~kg} / \mathrm{m}^{2}$ and $3(21.43 \%)$ had a BMI of less than $22 \mathrm{~kg} / \mathrm{m}^{2}$. In the group with nonadjacent fracture,
2 of 21 patients $(9.52 \%)$ had a BMI greater than $25 \mathrm{~kg} / \mathrm{m}^{2}$ and $12(57.14 \%)$ had a BMI of less than $22 \mathrm{~kg} / \mathrm{m}^{2}$.

The "new fracture" group and the "no fracture" group are compared in Table 3. The age, mean body height, mean body weight, mean BMI, mean volume of PMMA, intradiscal cement leakage, and the anterior/middle vertebral height restoration rate exhibited no significant differences between the "new fracture" group and the "no fracture" group. The T-score of the spinal BMD in the "new fracture" group was $-3.95 \pm 0.59$, while the BMD was $-2.86 \pm 0.55$ in the "no fracture" group $(P<$ $0.000)$. Morbidities of women were significantly higher in the "new fracture" group (94.29\%) compared with the group $(77.88 \%)(P=0.025)$.

To further clarify the relationship between risk factors and fractures, risk factors were also analyzed among the "no fracture" group, "adjacent fracture" group, and the "nonadjacent fracture" group. The mean body weight and the mean BMI in the "adjacent fracture" group were greater than in the "no fracture" group, although this difference was not statistically significant $(P>0.05)$ (Table 4$)$. The middle vertebral height restoration was smaller in the "no fracture" group (8.95\%) than in the "new 
Table 2. The comparison between the "nonadjacent fracture" group and the "adjacent fracture" group by constitutional factors.

\begin{tabular}{|l|c|c|c||}
\hline \multicolumn{1}{|c|}{ Variable } & Nonadjacent fracture group & Adjacent fracture group & P value \\
\hline Age (year) & $71.9 \pm 7.55$ & $70.21 \pm 8.46$ & 0.540 \\
\hline No. of female $(\%)$ & $20(95.2 \%)$ & $13(92.8 \%)$ & 1.000 \\
\hline Mean body height $(\mathrm{cm})$ & $154.29 \pm 5.25$ & $155.86 \pm 8.23$ & 0.494 \\
\hline Mean body weight $(\mathrm{kg})$ & $54.31 \pm 12.98$ & $61.39 \pm 17.15$ & 0.174 \\
\hline Mean BMI (kg/m $\left.{ }^{2}\right)$ & $22.70 \pm 4.83$ & $25.03 \pm 6.06$ & 0.216 \\
\hline Mean spinal BMD (T-score) & $-4.00 \pm 0.46$ & $-3.86 \pm 0.75$ & 0.475 \\
\hline PMMA volume (mL) & $3.48 \pm 1.08$ & $3.67 \pm 0.88$ & 0.507 \\
\hline Cement leakage into disk, $\mathrm{n}(\%)$ & $2(9.5 \%)$ & $2(14.3 \%)$ & 1.000 \\
\hline Anterior Vertebral height restoration (\%) & $7.22 \pm 10.82$ & $5.72 \pm 7.98$ & 0.584 \\
\hline Middle Vertebral height restoration $(\%)$ & $12.99 \pm 11.89$ & $9.29 \pm 8.92$ & 0.223 \\
\hline
\end{tabular}

BMI : body mass index, BMD : bone mineral density, PMMA : polymethylmethacrylate

Table 3. The comparison between the "new fracture" group and the "no fracture" group by constitutional factors.

\begin{tabular}{|l|c|c|c||}
\hline \multicolumn{1}{|c|}{ Variable } & New fracture group & No fracture group & P value \\
\hline Age (year) & $71.23 \pm 7.85$ & $69.98 \pm 8.78$ & 0.421 \\
\hline No. of female $(\%)$ & $33(94.29 \%)$ & $250(77.88 \%)$ & $0.025^{*}$ \\
\hline Mean body height $(\mathrm{cm})$ & $154.91 \pm 6.53$ & $156.14 \pm 6.37$ & 0.283 \\
\hline Mean body weight (kg) & $57.14 \pm 14.97$ & $55.07 \pm 8.13$ & 0.426 \\
\hline Mean BMI (kg/m $\left.{ }^{2}\right)$ & $23.63 \pm 5.39$ & $22.54 \pm 2.63$ & 0.242 \\
\hline Mean spinal BMD (T-score) & $-3.95 \pm 059$ & $-2.86 \pm 0.55$ & $0.000^{*}$ \\
\hline PMMA volume (ML) & $3.56 \pm 0.99$ & $3.69 \pm 1.03$ & 0.412 \\
\hline Cement leakage into disk, n (\%) & $4(11.4 \%)$ & $41(12.8 \%)$ & 1.000 \\
\hline Anterior Vertebral height restoration (\%) & $6.55 \pm 9.58$ & $8.97 \pm 11.63$ & 0.155 \\
\hline Middle Vertebral height restoration (\%) & $11.32 \pm 10.72$ & $8.95 \pm 10.34$ & 0.126 \\
\hline \hline
\end{tabular}

*Statistically significant. BMI : body mass index, BMD : bone mineral density, PMMA : polymethylmethacrylate

Table 4. The comparison between the "adjacent fracture" group and the "no fracture" group by constitutional factors.

\begin{tabular}{|l|c|c|c||}
\hline \multicolumn{1}{|c|}{ Variable } & Adjacent fracture group & No fracture group & P value \\
\hline Mean body weight $(\mathrm{kg})$ & $61.39 \pm 17.15$ & $55.07 \pm 8.13$ & 0.193 \\
\hline Mean BMI $\left(\mathrm{kg} / \mathrm{m}^{2}\right)$ & $25.03 \pm 6.06$ & $22.54 \pm 2.63$ & 0.149 \\
\hline Mean spinal BMD (T-score) & $-3.86 \pm 0.75$ & $-2.86 \pm 0.55$ & $0.000^{*}$ \\
\hline PMMA volume (mL) & $3.67 \pm 0.88$ & $3.69 \pm 1.03$ & 0.917 \\
\hline Anterior Vertebral height restoration (\%) & $5.72 \pm 7.98$ & $8.97 \pm 11.63$ & 0.188 \\
\hline Middle Vertebral height restoration (\%) & $9.29 \pm 8.92$ & $8.95 \pm 10.34$ & 0.877 \\
\hline
\end{tabular}

${ }^{\star}$ Statistically significant. BMI : body mass index, BMD : bone mineral density, PMMA : polymethylmethacrylate

fracture" group (12.99\%) $(P=0.049)$ (Table 5). Regardless of "adjacent fracture" or "nonadjacent fracture" status, the spinal BMDs were lower than the "no fracture" group $(P=0.000)$.

\section{Discussion}

PKP is an effective and widely accepted treatment for symptomatic vertebral compression fractures. However, vertebral body fractures following PKP have been reported recently. The reported incidence of new VCF following PKP ranges from $8 \%$ to $52 \%(1,5-7)$. The vast majority of new vertebral fractures following PKP are reported to develop in adjacent vertebrae. However, we find that new VCFs following PKP occurred most often in nonadjacent vertebrae. Despite relevant research, the cause of post-PKP VCF remains controversial. Therefore, the second aim of this study was to analyze the subsequent vertebral fractures and to establish a re- 
Pain Physician: November/December 2015; 18:565-572

Table 5. The comparison between the "nonadjacent fracture" group and the "no fracture" group by constitutional factors.

\begin{tabular}{|l|c|c|c|}
\hline \multicolumn{1}{|c|}{ Variable } & Nonadjacent fracture group & No fracture group & P value \\
\hline Mean body weight $(\mathrm{kg})$ & $54.31 \pm 12.98$ & $55.07 \pm 8.13$ & 0.690 \\
\hline Mean BMI $\left(\mathrm{kg} / \mathrm{m}^{2}\right)$ & $22.70 \pm 4.83$ & $22.54 \pm 2.63$ & 0.876 \\
\hline Mean spinal BMD (T-score) & $-4.00 \pm 0.46$ & $-2.86 \pm 0.55$ & $0.000^{*}$ \\
\hline PMMA volume (mL) & $3.48 \pm 1.08$ & $3.69 \pm 1.03$ & 0.301 \\
\hline Anterior Vertebral height restoration (\%) & $7.22 \pm 10.82$ & $8.97 \pm 11.63$ & 0.440 \\
\hline Middle Vertebral height restoration (\%) & $12.99 \pm 11.89$ & $8.95 \pm 10.34$ & $0.049^{*}$ \\
\hline
\end{tabular}

*Statistically significant. BMI : body mass index, BMD : bone mineral density, PMMA : polymethylmethacrylate

lationship between vertebral fractures and risk factors. New VCFs following PKP were previously reported to occur most often in adjacent vertebrae, and adjacent fractures were found to occur at significantly shorter intervals than nonadjacent fractures $(6,8,9)$. In our study, new VCFs at nonadjacent levels were more frequent than adjacent fractures. Out of 35 new post-PKP VCFs, $21(60 \%)$ were nonadjacent fractures, compared with $14(40 \%)$ adjacent fractures. In addition, we found that adjacent vertebral fractures did not occur at shorter intervals than did nonadjacent vertebral fractures. In the "adjacent fracture" group, 3 patients had new fractures within a month and 4 had new fractures within 3 months. However, the number of new fractures was the same in the "nonadjacent fracture" group. According, kyphoplasty should not be considered as a major cause of adjacent vertebral fractures.

Osteoporosis is a risk factor for the development of vertebral fractures $(10,11)$. Our results also indicate that a lower BMD is an important factor for post-PKP VCF. The average spine BMD was -3.95 in the "new fracture" group and -2.86 in the "no fracture" group $(P<0.05)$. We suggest that demineralizing spinal degeneration is an important risk factor. Uppin et al (6) noted that when osteoporosis worsened, patients were more likely to develop new fractures in adjacent vertebrae. However, we find no significant differences in BMD between the "adjacent fracture" group and the "nonadjacent fracture" group. Spinal BMD was -3.86 in the "adjacent fracture" group and -4.0 in the "nonadjacent fracture" group $(P=0.47)$. The BMDs of the "nonadjacent fracture" group (-4.0) and the "no fracture" group (-2.86) were significantly different $(P=0.000)$. This result indicates that a low spinal BMD is a risk factor.

Gender was another risk factor for subsequent fractures. It is generally accepted that women are more prone to suffer from VCF $(12,13)$. In the current study, $283(79.49 \%)$ patients were women, and $33(11.66 \%)$ of them suffered a new fracture. However, only $2(2.74 \%)$ men experienced new VCF $(P<0.05)$. Our results indicate that women are more susceptible to subsequent fracture compared with men.

Many investigators believe that low BMI and low body weight increase the incidence of new vertebral fractures $(14,15)$. Thin people are more likely to develop osteoporosis and VCFs (16). Lin et al (16) reported that patients with a BMI less than $22 \mathrm{~kg} / \mathrm{m}^{2}$ had a greater chance of developing new VCFs after vertebroplasty. In our study, low BMI was a significant predictor of nonadjacent fractures after kyphoplasty, especially when the BMI was less than $22 \mathrm{~kg} / \mathrm{m}^{2}$. However, we also found that a patient was more likely to incur an adjacent vertebral fracture when his or her BMI was greater than $25 \mathrm{~kg} / \mathrm{m}^{2}$.

Many authors believe that intradiscal cement leakage could be a risk factor for subsequent vertebral body fractures $(5,17,18)$. They reported that intradiscal cement leakage increased subsequent fracture in an already weakened disc. However, the current study did not show a significant difference in intradiscal cement leakage between the "no fracture" group and the "new fracture" group. In addition, we find that higher restoration rates increased the risk of adjacent vertebral fractures. However, there were no significant differences between the "no fracture" group and the "adjacent fracture" group.

The cement volume was an important issue for PKP. A large volume of cement may fill the void in the vertebral body, but it could also increase the stress on adjacent vertebral bodies and thus increase the risk for new vertebral body fractures. It is reported that higher instances of fracture occur after large volumes of cement are injected $(19,20)$. This claim has been disputed since other investigators insist that there is no specific relationship between cement volume and subsequent vertebral body fractures $(21,22)$. We find a greater number of adjacent vertebral body fractures in association with higher BMI and higher gross weight. 
An initial multi-segment kyphoplasty was an important risk factor for new vertebral body fracture. In our study, 62 (19.31\%) patients had multi-segment kyphoplasty in the "no fracture" group and 16 (45.71\%) patients had multi-segment kyphoplasty in the "new fracture" group $(P<0.01)$. In the "adjacent fracture" group, $9(64.3 \%)$ patients had multi-segment kyphoplasty, while there were 7 patients $(33.3 \%)$ with multisegment kyphoplasty in the "nonadjacent fracture" group $(P=0.094)$.

Our study was limited in that it was retrospective, and our data were obtained from only one institution. Our study was also limited in that we did not have information regarding the outcomes of patients with new vertebral body fractures that were treated conservatively. This limits our estimates of the incidence of subsequent vertebral body fracture.

\section{Conclusion}

We analyzed the patterns and risk factors of subsequent VCF following PKP. We found that adjacent vertebral fractures following PKP were not more common than nonadjacent ones and did not occur at a shorter interval than did nonadjacent ones. In our study, nonadjacent vertebral fractures following PKP occurred more frequently than adjacent vertebral fractures. We found that an initial multi-segment kyphoplasty resulted in a higher incidence of new vertebral body fractures, especially in the adjacent vertebral body. Low vertebral body mineral density was a major risk factor in the development of new VCFs following PKP. Elderly women were found to be more susceptible than elderly men to new VCFs following PKP. The data regarding $B M D$ support the importance of treatment methods to improve bone mineral density before and after PKP.

\section{Author Contributions}

Dr. Lei Ning had full access to all the data in the study and takes responsibility for the integrity of the data and the accuracy of the data analysis. Drs. Chao Liu, Zhaobo Huang, Hongxin Cai, and Shunwu Fan designed the study protocol. Dr. Lei Ning managed the literature searches and summaries of previous related work and wrote the first draft of the manuscript. Dr. Shuanglin Wan provided revision for intellectual content and final approval of the manuscript.

\section{Conflict of Interest}

All authors have no conflicts of interest to report. None of the authors of the manuscript received any remuneration. Further, the authors have not received any reimbursement or honorarium in any other manner. Dr. Shuanglin Wan is the Funding/Support. The authors wish to disclose and thank the sponsor of the study. The study was conducted by Dr. Shuanglin Wan. The study was conducted by Dr. Shuanglin Wan. The study was sponsored by Office of Education in Zhejiang Province (Grant Number: Y201121005) and Science and Technology Agency in Zheji-ang Province( Grant Number: 2013C33237). The sponsorship was limited to supplies and expenses. The sponsorship included payment for employees for data collection, data entry, and analysis of the data. They had no influence or interference after the protocol was designed.

\section{Role of Sponsor}

The financial sponsor of this work had no role in the design and conduct of the study or the collection, management, analysis, and interpretation of the data. The sponsor also did not have a role in the preparation or review of the manuscript or the decision to submit. We also would like to thank the editorial board of Pain Physician for review and criticism in improving the manuscript.

\section{References}

1. Grados F, Depriester C, Cayrolle G, Hardy N, Deramond H, Fardellone P. Longterm observations of vertebral osteoporotic fractures treated by percutaneous vertebroplasty. Rheumatology (Oxford) 2000; 39:1410-1414.

2. Heini PF, Wälchli B, Berlemann U. Percutaneous transpedicular vertebroplasty with PMMA: Operative technique and early results. A prospective study for the treatment of osteoporotic compression fractures. Eur Spine J 2000; 9445-450.

3. Ananthakrishnan D, Berven $S$, Deviren V, Cheng K, Lotz JC, Xu Z, Puttlitz CM.
The effect on anterior column loading due to different vertebral augmentation techniques. Clin Biomech (Bristol, Avon) 2005; 20:25-31.

4. Lindsay R, Burge RT, Strauss DM. One year outcomes and costs following a vertebral fracture. Osteoporos Int 2005; 16:78-85.

5. Berlemann U, Ferguson SJ, Nolte LP, Heini PF. Adjacent vertebral failure after vertebroplasty: A biomechanical investigation. J Bone Joint Surg $\mathrm{Br} 2002$; 84:748-752.

6. Uppin AA, Hirsch JA, Centenera LV, Pfief- er BA, Pazianos AG, Choi IS. Occurrence of new vertebral body fracture after percutaneous vertebroplasty in patients with osteoporosis. Radiology 2003; 226:119-124.

7. Voormolen $\mathrm{MH}$, Lohle PN, Juttmann JR, van der Graaf Y, Fransen H, Lampmann LE. The risk of new osteoporotic vertebral compression fractures in the year after percutaneous vertebroplasty.] VascInterv Radiol 2006; 17:71-76.

8. Ross PD, Davis JW, Epstein RS, Wasnich RD. Pre-existing fractures and bone mass predict vertebral fracture inci- 
dence in women. Ann Intern Med 1992; 114: 919-923.

9. Trout AT, Kallmes DF, Kaufmann TJ. New fractures after vertebroplasty: Adjacent fractures occur significantly sooner. AJNR Am J Neuroradiol 2006; 27:217-223.

10. Ralston SH, Uittlerlinden AG. Genetics of osteoporosis. Endocr Rev 2010; 31:629-662.

11. Kim SH, Kang HS, Choi JA, Ahn JM.Risk factors of new compression fractures in adjacent vertebrae after percutaneous vertebroplasty. Acta Radiol 2004; 45:440-445.

12. Komemushi A, Tanigawa N, Kariya $S$, Kojima H, Komemushi S, Shomura Y, Sawada S. Percutaneous vertebroplasty for osteoporotic compression fracture: Multivariate study of predictors of new vertebral body fracture. Cardiovasc Intervent Radiol 2006; 29:580-585.

13. Fujiwara S, Kasagi F, Yamada M, Kodama K. Risk factors for hip fracture in a Japanese cohort.] Bone Miner Res 1997; 12:998-1004.
14. Thomas T, Barou O, Vico L, Alexandre $\mathrm{C}$, Lafage-Proust $\mathrm{MH}$. Recurrence of vertebral fracture with cyclical etidronate therapy in osteoporosis: Histomorphometry and $\mathrm{x}$-ray microanalysis evaluation. J Bone Miner Res 1999; 14:198-205.

15. Ooms ME, Lips $P$, Van Lingen A, Valkenburg HA. Determinants of bone mineral density and risk factors for osteoporosis in healthy elderly women. J Bone Miner Res 1993; 8:669-675.

16. Lin WC, Cheng TT, Lee YC, Wang TN, Cheng YF, Lui CC, Yu CY. New vertebral osteoporotic compression fractures after percutaneous vertebroplasty: Retrospective analysis of risk factors. J Vasc Interv Radiol 2008; 19:225-231.

17. Chen WJ, Kao YH, Yang SC, Yu SW, Tu YK, Chung KC. Impact of cement leakage into disks on the development of adjacent vertebral compression fractures. J Spinal Disord Tech 2010; 23:35-39.

18. Rho YJ, Choe WJ, Chun YI. Risk factors predicting the new symptomatic vertebral compression fractures after percu- taneous vertebroplasty or kyphoplasty. Eur Spine J 2012; 21:905-911.

19. Baroud G, Heini P, Nemes J, Bohner $M$, Ferguson S, Steffen T. Biomechanical explanation of adjacent fractures following vertebroplasty. Radiology 2003; 229:606-607.

20. Berlemann U, Ferguson SJ, Nolte LP, Heini PF. Adjacent vertebral failure after vertebroplasty. A biomechanical investigation. J Bone Joint Surg $\mathrm{Br}$ 2002; 84:748-752.

21. Lindsay R, Burge RT, Strauss DM. One year outcomes and costs following a vertebral fracture. Osteoporos Int 2005; 16:78-85.

22. Chai Min Yoo, Kyung Bum Park, Soo Hyun Hwang, Dong Ho Kang, Jin Myung Jung, In Sung Park. The analysis of patterns and risk factors of newly developed vertebral compression fractures after percutaneous vertebroplasty. J Korean Neurosurg Soc 2012; 52:339-345. 